\title{
Research on passenger flow forecast of Urban Rail Transit
}

\author{
Xiao $\mathrm{Li}^{1}$ \\ ${ }^{1}$ Department of Transportation, CUCD, Beijing, 100088, China
}

\begin{abstract}
Urban rail transit has the characteristics of large traffic volume, fast and convenient, so it has become the urban passenger transport mode which is given priority in the planning and design of each city. The prediction and analysis of rail transit passenger flow is a very important part in the planning and design stage. And it also provides important basic data for urban rail planning, construction and operation. When the rail transit network needs to be adjusted, the passenger flow forecast is also an essential step. In this paper, Taking Dongguan urban rail transit line 2 as an example, based on the full consideration of the uniqueness of Dongguan urban rail transit and the prediction of various social and economic indicators of Dongguan City, the "four step method" is adopted to forecast passenger flow. Through the investigation of resident's travel survey, we can master the current travel distribution of all modes. Based on the analysis of land use change, traffic development policy and related influencing factors of Dongguan City, the trip distribution of each characteristic year is predicted. Then, the OD matrix of public transport (including subway and conventional public transport) is obtained through the study of traffic mode division model, and the predicted rail passenger flow is obtained through the allocation model of cooperation and competition. In the stage of passenger flow assignment, the influence of various factors on travel route selection is comprehensively considered in the public transport allocation model. Finally, the prediction index and sensitivity of rail passenger flow are analyzed.
\end{abstract}

\section{Introduction}

The proposal of Outline Development Plan for the Guangdong-Hong Kong-Macao Greater Bay Area and approval of Construction planning for the GuangdongHong Kong-Macao Greater Bay Area are both a rare opportunity to realize higher level development in Dongguan, which is in the central position of the Great Bay Area in both geographical and economic sense. Dongguan should make full use of the advantages of high speed and large traffic volume of urban rail transit to form a transportation development mode of "cohesion and external connection". At the regional level, Dongguan should build an hour traffic circle with the cities in the Pearl River Delta, and realize that the average travel time of residents at the city level should not exceed 45 minutes.

\section{Traffic demand forecast}

\subsection{Important premise of passenger flow forecast}

\subsubsection{Land use along the track project in the near} future. According to the spatial structure of the master plan, the development intensity of the area covered by the line network in the near future is divided into three steps.
Based on different development strategies, plot ratio and station hinterland of general areas along the track are preliminarily determined.

2.1.2. Population and employment. The prediction of the scale and distribution of population and employment is one of the preconditions for the prediction of rail passenger flow and distribution. The population size, population structure, travel and employment intensity of different population groups should be fully considered in predictions.

\subsubsection{Establishment of road and public transport network model. For conventional bus network, the excessive density of conventional bus will reduce the attraction of rail transit. Therefore, in the process of passenger flow distribution, the optimized bus layout is adopted to adjust the over competitive routes. Important passenger distribution points should also be considered, which have important influence on the generation and attraction of passenger flow and the distribution of passenger flow.}

\subsection{Traffic demand model}

2.2.1. Traffic zoning. Fully consider the geographical location, geographical conditions, economic development, 
the layout of the main roads and urban spatial structure to form a traffic zoning system. According to the results of land use survey and related planning along the rail station, the traffic districts around the station are subdivided to meet the accuracy requirements of rail passenger flow model.

2.2.2. Trip generation. The travel occurrence and attraction model of traffic district is to predict the travel volume that the population with specific social and economic characteristics may generate in each traffic area. The method of category generation rate is usually used.

2.2.3. Trip distribution. Establishing A traffic distribution model based on gravity model. According to different travel purposes, the distribution models are established respectively. The PA calculated by the calibrated model is checked with the PA table of current situation investigation.

2.2.4. Travel mode Division. The method of combining macro and micro analysis is used to determine the mode division model of each characteristic year in the future. The validity of the model can be judged by the coincidence between the model calculation and the survey value.

\section{Case Study of Dongguan Urban Rail Transit line 2}

\subsection{Background}

3.1.1. Geographical location analysis. Dongguan is located in the south central part of Guangdong Province, the northeast of Pearl River Delta and the East Bank of Pearl River Estuary. It is $50 \mathrm{~km}$ away from Guangzhou in the north and $90 \mathrm{~km}$ away from Shenzhen in the south. It is 47 nautical miles to Hong Kong and 48 nautical miles to Macao. It is in the middle of the Guangzhou Hong Kong Economic Corridor and is the only place for land and water transportation between Guangzhou and Hong Kong. With the sustained and rapid development of social economy in Dongguan, the scale of urban construction land is also expanding, and the construction land of the whole city is decreasing day by day.

3.1.2. Social and economic situation. Judging from the growth rate over the years, taking 2007 as the boundary, the growth rate has been maintained at more than $18 \%$ and then dropped sharply. After five years of fluctuation, the growth rate has been maintained at about $8.0 \%$ since 2013, which indicates that Dongguan's economy has adapted to the new situation and the growth rate has basically stabilized. In 2019, the GDP of Dongguan will reach 948.250 billion yuan, with a year-on-year growth of $7.4 \%$ at comparable prices, which is higher than the national $(6.1 \%)$ and provincial $(6.2 \%)$ average levels in the same period.

3.1.3. Current situation of urban traffic. The road network of Dongguan City is well developed, and the city and town streets are mainly connected with national and provincial roads through expressways. Expressways and national and provincial roads constitute the basic framework of road network in Dongguan City with the old urban area as the center.

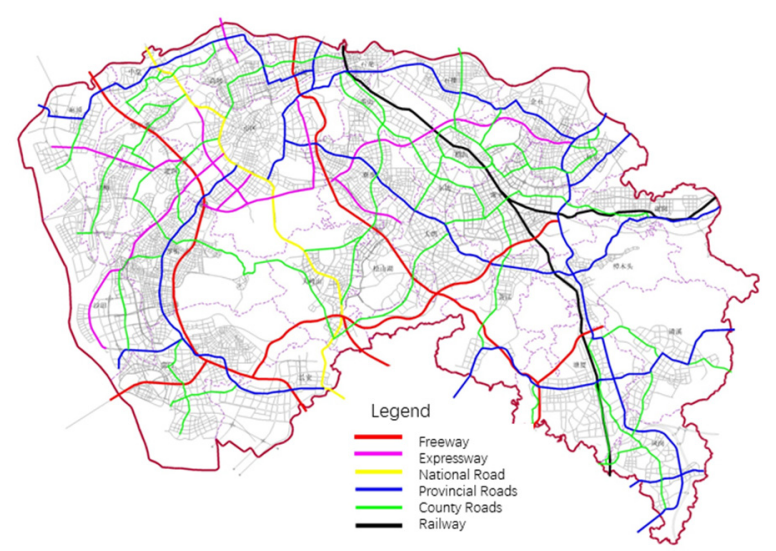

Figure 1. Distribution of administrative grade of existing highways in Dongguan City

According to the big data analysis report of public transport in major cities of China in 2017, the scale of public transport lines in Dongguan reached 448, the route length reached $9000 \mathrm{~km}$, and the coverage rate of $500 \mathrm{~m}$ stops reached $79 \%$, ranking the 12 th among domestic cities. $n$ the statistics of passenger traffic volume of public transport mode, public transport accounted for the largest proportion, reaching $64.07 \%$, while subway accounted for the lowest proportion of $6.52 \%$.

\subsection{Traffic demand analysis}


3.2.1. Total travel volume and distribution. In 2030, the forecast of the number of trips per capita in Dongguan is shown in Table 1. In the future, the difference between the per capita travel intensity of household population and that of collective household population will gradually narrow, and the number of trips of floating population will same for long.

Table 1. Travel volume forecast in 2030 and future years.

\begin{tabular}{lcccccc}
\hline & $\begin{array}{c}\text { Population } \\
\text { (million) }\end{array}$ & $\begin{array}{c}\text { Frequency } \\
\text { (times / day) }\end{array}$ & $\begin{array}{c}\text { Volume } \\
\text { (million/day) }\end{array}$ & $\begin{array}{c}\text { Population } \\
\text { (million) }\end{array}$ & $\begin{array}{c}\text { Future Years } \\
\text { Frequency } \\
\text { (times / day) }\end{array}$ & $\begin{array}{c}\text { Volume } \\
\text { (million/day) }\end{array}$ \\
$\begin{array}{l}\text { Family } \\
665\end{array}$ & 2.80 & 1862 & 850 & 2.70 & 2295 \\
$\begin{array}{l}\text { Collective } \\
\text { household }\end{array}$ & 285 & 2.00 & 570 & 200 & 2.50 & 500 \\
$\begin{array}{l}\text { Floating } \\
\text { population }\end{array}$ & 50 & 3.00 & 150 & 80 & 3.00 & 240 \\
$\begin{array}{l}\text { Hub travel } \\
\text { Total }\end{array}$ & & & 50 & & & 80 \\
\hline
\end{tabular}

In terms of traffic attraction, Humen, Changping and urban areas are the main destinations for family residents to travel. Among them, public construction employment is the main attraction for urban and Changping Town, while industrial employment is the main attraction for Humen Town. For Chang'an Town, household employment attraction is relatively small.

Table 2. Travel attraction forecast of towns and streets in 2030 and future years (part).

\begin{tabular}{|c|c|c|c|c|c|c|c|c|}
\hline \multirow{2}{*}{$\begin{array}{l}\text { Towns and } \\
\text { Streets }\end{array}$} & \multicolumn{4}{|c|}{2030 (million/day) } & \multicolumn{4}{|c|}{ Future Years (million/day) } \\
\hline & $\begin{array}{l}\text { Office } \\
\text { land }\end{array}$ & $\begin{array}{l}\text { Commercial } \\
\text { land }\end{array}$ & $\begin{array}{l}\text { Industrial } \\
\text { land }\end{array}$ & Others & Office land & $\begin{array}{l}\text { Commercial } \\
\text { land }\end{array}$ & Industrial land & Others \\
\hline Guancheng & 10.3 & 8.6 & 0.1 & 2.9 & 12.5 & 10.7 & 0.1 & 4.3 \\
\hline Dalang & 17.4 & 15.1 & 7.0 & 4.4 & 21.2 & 18.8 & 6.4 & 6.6 \\
\hline Changping & 22.1 & 9.2 & 6.9 & 6.8 & 26.8 & 11.4 & 6.3 & 10.2 \\
\hline Humen & 29.2 & 52.9 & 18.3 & 10.3 & 35.5 & 65.8 & 16.7 & 15.3 \\
\hline Houjie & 19.5 & 30.0 & 22.1 & 5.0 & 23.8 & 37.2 & 20.1 & 7.4 \\
\hline Chang'an & 30.5 & 36.7 & 37.1 & 9.6 & 37.0 & 45.6 & 33.7 & 14.3 \\
\hline
\end{tabular}

3.2.2. Travel space distribution. In the planning year, the trend of spatial distribution of residents' travel in Dongguan presents as following:

a. Travel distance growth: With the development of regional integration and motorization in Dongguan City, Chang'an, Humen and other regions, the traffic links between towns are increasingly close, and the travel time and distance have increased.

b. Travel demand growth among major groups: The travel intensity among Northwest group, central group and southwest group is larger, while the travel intensity between northwest group and northeast group, southwest group and Southeast group is the lowest.

c. In terms of the spatial distribution pattern of travel, the traffic trips are mainly concentrated between the northwest group, the central group and the southwest group.

3.2.3. Proportion of modes of transportation. After the ban on motorcycles in Dongguan, motorcycles will be transferred to cars and bicycles, and the proportion is shown in Table 3.

Table 3. Travel mode composition of Dongguan residents in 2030.

\begin{tabular}{lccccccc}
\hline Mode & \multicolumn{2}{c}{ Non-Motorized } & \multicolumn{3}{c}{ Motorized } & & \\
& Walk & Bike & Public transit & Motor & Private car & Taxi & Others \\
Average & $25^{\sim} 30 \%$ & $12^{\sim} 15 \%$ & $25^{\sim} 30 \%$ & $3 \%$ & $20 \sim 25 \%$ & $2 \sim 3 \%$ & $3 \sim 4 \%$ \\
\hline
\end{tabular}


3.2.4. Traffic assignment. it is not significant to use the horizontal distance between two points as the transfer distance. It is necessary to introduce the concept of actual

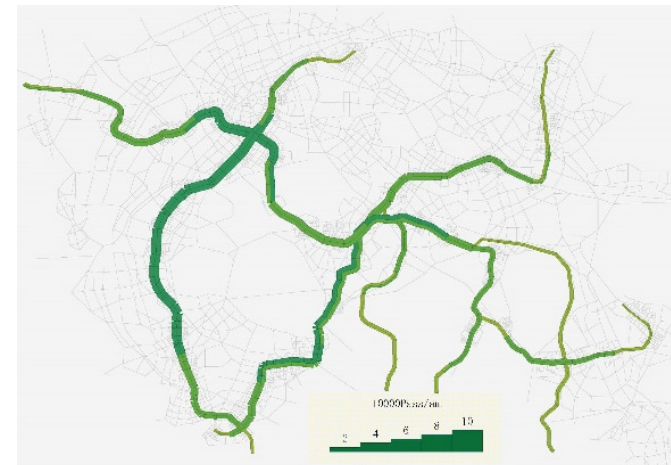

walking distance to help define the transfer distance. In the study, the actual walking distance is defined as the sum of the total length of the road around which two points need to be connected by walking in space.

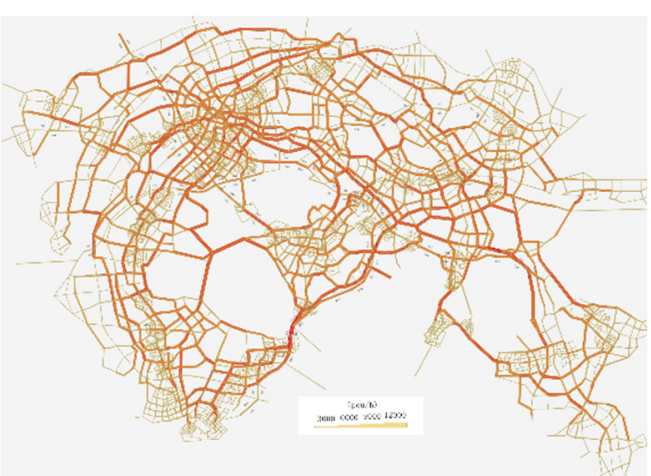

Figure 2. Distribution of rail transit passenger flow (left) and motor vehicle flow (right) in the morning peak of the future year

\subsection{Passenger flow forecast}

3.3.1. Overall line index. The main technical indicators of Dongguan urban rail transit line 2 are shown in Table
4. The maximum one-way section passenger flow at the initial stage is 11900 person times / $\mathrm{h}$, in the direction of Dongguan Shenzhen border Dongguan railway station, and between Dongcheng station and Tianbao station.

\section{Table 4. Main technical indexes of Dongguan Rail Transit Line 2}

\begin{tabular}{|c|c|c|c|c|}
\hline \multirow{2}{*}{ Times } & Index & FUTURE YEAR & 2035 年 & 2024 年 \\
\hline & Length（km） & 57.1 & 57.1 & 57.1 \\
\hline \multirow{7}{*}{ Full-time } & Volume (million/day) & 104.02 & 96.78 & 68.53 \\
\hline & Passenger-km(million.km/day) & 1366.11 & 1212.41 & 638.45 \\
\hline & Load intensity（million/km.day) & 1.82 & 1.69 & 1.20 \\
\hline & Passenger Intensity（ millio.km/km.day） & 23.92 & 21.23 & 11.18 \\
\hline & $\begin{array}{l}\text { Maximum one-way section flow (million } \\
\text { /day) }\end{array}$ & 16.79 & 15.08 & 7.89 \\
\hline & Average Distance $(\mathrm{km})$ & 13.13 & 12.53 & 9.32 \\
\hline & Connection Volume（million/day） & 8.29 & 6.44 & 0.95 \\
\hline \multirow{8}{*}{$\begin{array}{l}\text { Morning } \\
\text { peak }\end{array}$} & Volume（million/day） & 14.95 & 14.04 & 10.08 \\
\hline & Passenger-km(million.km/day) & 196.12 & 175.65 & 93.52 \\
\hline & Load intensity（million/km.day） & 0.26 & 0.25 & 0.18 \\
\hline & Passenger Intensity（millio.km/km.day） & 3.43 & 3.08 & 1.64 \\
\hline & $\begin{array}{c}\text { Maximum one-way section flow (million } \\
\text { /day) }\end{array}$ & 2.47 & 2.24 & 1.19 \\
\hline & Average Distance $(\mathrm{km})$ & 13.12 & 12.51 & 9.28 \\
\hline & Connection Volume（million/day） & 1.18 & 0.94 & 0.14 \\
\hline & $\operatorname{PHF}(\%)$ & 14.37 & 14.50 & 14.71 \\
\hline \multirow{8}{*}{$\begin{array}{l}\text { Evening } \\
\text { peak }\end{array}$} & Volume（million/day） & 14.37 & 13.50 & 9.69 \\
\hline & Passenger-km(million.km/day) & 188.63 & 168.96 & 89.98 \\
\hline & Load intensity（million/km.day） & 0.25 & 0.24 & 0.17 \\
\hline & Passenger Intensity（millio.km/km.day） & 3.30 & 2.96 & 1.58 \\
\hline & $\begin{array}{c}\text { Maximum one-way section flow (million } \\
\text { /day) }\end{array}$ & 2.37 & 2.15 & 1.15 \\
\hline & Average Distance $(\mathrm{km})$ & 13.13 & 12.52 & 9.28 \\
\hline & Connection Volume（million/day） & 1.13 & 0.91 & 0.14 \\
\hline & $\operatorname{PHF}(\%)$ & 13.81 & 13.95 & 14.14 \\
\hline
\end{tabular}


3.3.2. Station passenger volume and cross-section passenger flow. Taking the future years of line 2(Dongguan-Shenzhen Boundary - Dongguan Railway
Station Direction and Dongguan Railway Station Dongguan-Shenzhen Boundary Direction) for example, the upstream and downstream passenger volume and cross-section passenger flow during the whole day, morning and evening peak are shown in the figure below.
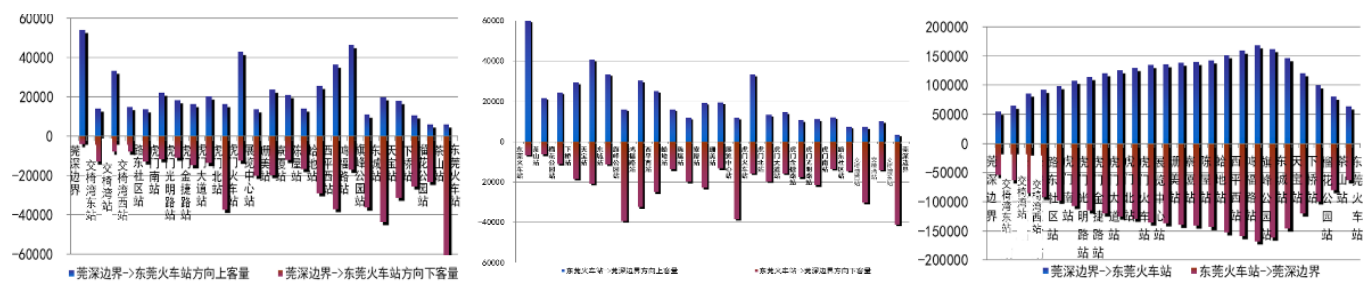

Figure 3. Full day boarding and alighting passenger volume of long-term(left) and short-term(middle) and whole day section passenger flow(right) of line 2
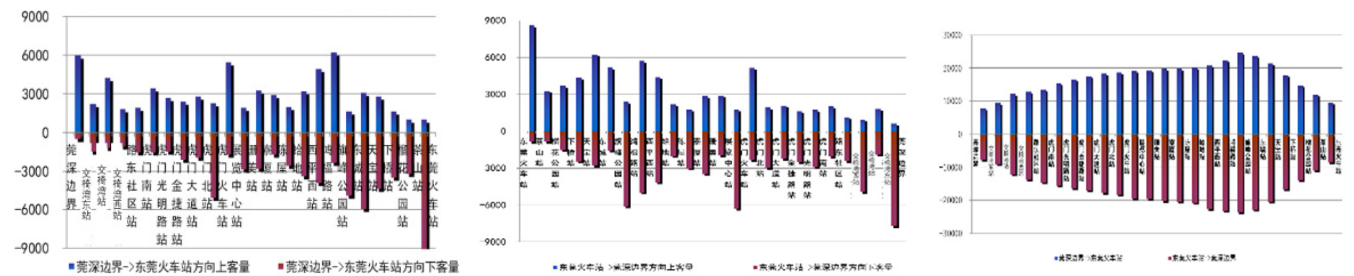

Figure 4. Section passenger flow and station boarding and landing volume of line 2 (morning peak in the long term)
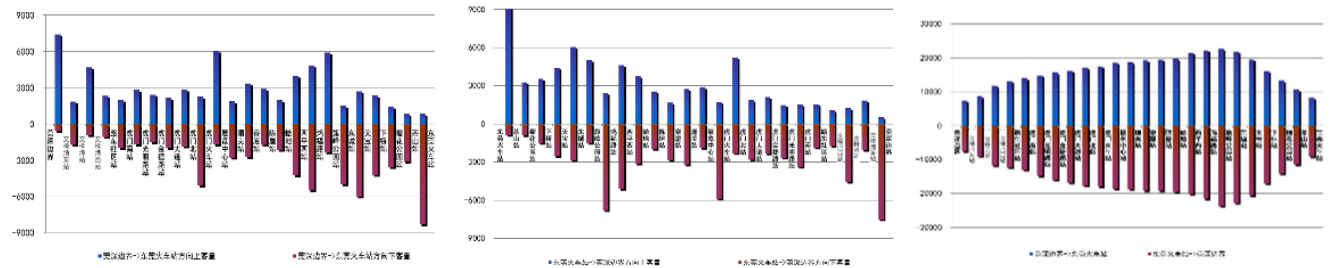

Figure 5. Section passenger flow and station boarding and landing volume of line 2 (evening peak in the long term)

\section{Conclusion}

Based on the residents' travel survey and traffic survey, this paper uses scientific forecasting methods to forecast the daily average passenger flow, the maximum section person times in one-way peak hours, the whole day turnover and the average transportation distance of Dongguan urban rail transit line 2, which can provide data basis for the planning and design in the next stage. It can provide data basis for the planning and design of the next stage, and also provide basis for effective planning and organization of train scheduling and time interval during operation. In the next stage, passenger flow sensitivity analysis and social benefit evaluation should be carried out, so as to achieve the optimal operation organization effect.

\section{References}

1. Outline Development Plan for the Guangdong-Hong Kong-Macao Greater Bay Area

2. Construction planning for the Guangdong-Hong Kong-Macao Greater Bay Area
3. Li, N.Y., (2018) Passenger flow forecast and analysis of Lanzhou rail transit, Qinghai traffic science and technology,05: 20-24

4. Zhang, C., (2004) Analysis on the characteristics of urban rail transit passenger flow, Southwest Jiaotong University, 31-37

5. Tan, G.W., Zong, C. L, (2013) Analysis and Enlightenment of passenger flow characteristics of Shenzhen rail transit, 11(6): 46-47. 